\title{
Experimental study on mechanical properties of laminated steel fiber rubber concrete
}

\author{
SUN Jie ${ }^{1}$,, CHEN Guozhen ${ }^{1}$,WANG Anning ${ }^{1}$, LV Kangqi ${ }^{1}$, LUO Yi ${ }^{2}$ \\ 1. College of Urban Construction, the University of Wuhan Science and Technology, Wuhan, 430046,China; \\ ${ }^{2}$ Suzhou Zhongtong Planning and Design Corporation, Suzhou, 215131, China) \\ Correspondence address: Wuhan University of Science and Technology, Qingling Street, Hongshan District, Wuhan City, Hubei Province, \\ China
}

\begin{abstract}
In order to research the effect of the steel fiber volume and the rubber powder diameter on the mechanics performance of the layer steel fiber reinforced rubber concrete, the cube compression tests, splitting tensile tests and four-point bending tests are performed on steel fiber reinforced rubber concrete with steel fiber content of $0.5 \%, 1 \%, 1.5 \%, 2 \%, 2.5 \%$ and rubber powder mesh $20,40,60$. When 40 mesh rubber powder is added and the volume ratio of steel fiber is $1.5 \%$, the compressive strength of laminated steel fiber rubber concrete reaches the peak value. The splitting tensile strength of laminated steel fiber rubber concrete mixed with $2.0 \%$ steel fiber and mesh 40 rubber powder is the best. The flexural strength of laminated steel fiber rubber concrete mixed with $2.5 \%$ steel fiber and mesh 40 rubber powder is highest in this paper.
\end{abstract}

\section{Introduction}

With the rapid development of the transportation industry, the number of waste rubber tires is increasing. In order to solve the problem of waste tires, rubber tires are decomposing and made into rubber particles and mixed into concrete, so that it has the advantages of light weight, high elasticity, impact resistance and good crack resistance.Due to the flexible characteristics of rubber particles themselves will lead to the reduction of concrete strength, so the rubber concrete is mixed with steel fiber to achieve the purpose of strengthening the strength of rubber concrete.Zhang Xianggang and Zhu Jiang et al. ${ }^{[1-3]}$ Through the experimental study of steel fiber rubber concrete, it is found that the crack time of rubber concrete specimen is short and the width is small.Zhou Dong et al. ${ }^{[4]}$ changed the particle size and mixing amount of rubber particles and found that the greater the mixing amount of rubber particles, the lower the compressive strength of concrete. Yang Biao et al. ${ }^{[5]}$ found that the larger the size of mixed rubber particles was, the greater the influence of concrete's flexural strength would be.Hussein ${ }^{[6]}$ studied the flexural performance of steel fiber rubber concrete and found that rubber powder had an influence on the elastic coefficient of concrete, and the steel fiber also played a certain role.Fan Xiaochun ${ }^{[7]}$ compared and analyzed laminated SFRC with ordinary concrete, rubber concrete and laminated SFRC, and proved that laminated SFRC can effectively improve the mechanical properties, deformation properties and durability of ordinary concrete..

\section{Experimental design}

\section{1 the raw material}

Cement is P.C42.5 composite Portland cement of Wuhan Huaxin Cement Co., Ltd.The fine aggregate is common river sand (medium sand) with an apparent density of $2.54 \mathrm{~g} / \mathrm{cm} 3$, a fineness modulus of 2.91 and a bulk density of $1445 \mathrm{~kg} / \mathrm{m} 3$.Coarse aggregate adopts continuous grading marble gravel, rough surface, the maximum particle size of $20 \mathrm{~mm}$. The daily tap water is used for mixing water.The water reducing agent is HSC polycarboxylic acid high performance water reducing agent produced by Qingdao Hongsha Polymer Materials Co., Ltd., with a water reducing efficiency of $25 \%$.Rubber powder particles are 20 mesh, 40 mesh and 60 mesh rubber powder produced by Dujiangyan Huayi Rubber Co., Ltd.The steel fiber is the milling wavy steel fiber produced by Hebei Hengshui Shengze Building Materials Co., Ltd. The length is $38 \mathrm{~mm}$, the thickness is $0.6 \mathrm{~mm}$, the width is $2 \mathrm{~mm}$, the tensile strength is $644 \mathrm{MPa}$, and the mass density is $7950 \mathrm{~kg} / \mathrm{m}^{3}$.

\section{2 mixture ratio}

According to JGJ 55 -- 2011 "ordinary concrete mix ratio design regulations" and GB 50119 -- 2013 "concrete admixture application technical specifications" this test on concrete for many times scientific trial, and finally determined.The water-cement ratio was set as 0.34 , and the specific coordination was shown in Table 1. 
Table1. Mixture ratio of various types of concrete $\left(\mathrm{kg} / \mathrm{m}^{3}\right)$

\begin{tabular}{ccccccccc}
\hline $\begin{array}{c}\text { Specimen } \\
\text { number }\end{array}$ & $\begin{array}{c}\text { cement } \\
(\mathrm{kg})\end{array}$ & $\begin{array}{c}\text { sand } \\
(\mathrm{kg})\end{array}$ & $\begin{array}{c}\text { stone } \\
(\mathrm{kg})\end{array}$ & $\begin{array}{c}\text { water } \\
(\mathrm{kg})\end{array}$ & $\begin{array}{c}\text { water } \\
\text { reducer } \\
(\mathrm{kg})\end{array}$ & $\begin{array}{c}\text { rubber } \\
\text { powder } \\
(\mathrm{kg})\end{array}$ & $\begin{array}{c}\text { Volume ratio of } \\
\text { steel fiber }\end{array}$ & \begin{tabular}{c} 
Top \\
\cline { 5 - 8 }
\end{tabular} \\
\hline CC & 463 & 586 & 1190 & 158 & 3.6 & - & - & - \\
RCm & 463 & 586 & 1190 & 158 & 3.6 & 23.15 & - & - \\
LSm-0.5 & 463 & 586 & 1190 & 158 & 3.6 & 23.15 & $0.5 \%$ & $2.0 \%$ \\
LSm-1.0 & 463 & 586 & 1190 & 158 & 3.6 & 23.15 & $1.0 \%$ & $2.0 \%$ \\
LSm-1.5 & 463 & 586 & 1190 & 158 & 3.6 & 23.15 & $1.5 \%$ & $2.0 \%$ \\
LSm-2.0 & 463 & 586 & 1190 & 158 & 3.6 & 23.15 & $2.0 \%$ & $2.0 \%$ \\
LSm-2.5 & 463 & 586 & 1190 & 158 & 3.6 & 23.15 & $2.5 \%$ & $2.0 \%$ \\
\hline
\end{tabular}

Note: CC for ordinary concrete, RC for rubber concrete, LS for laminated steel fiber rubber concrete; In $\mathrm{RCM}, \mathrm{m}$ is the mesh number of rubber powder, with values of 20, 40 and 60 respectively. In LS m-n, $m$ is the number of rubber powder mesh, with values of 20,40 and 60 respectively; $\mathrm{N}$ is the volume ratio of upper steel fiber.

\subsection{Test methods}

In this test, non-standard cube specimens of $100 \mathrm{~mm} \times 100 \mathrm{~mm} \times 100 \mathrm{~mm}$ were poured using a forced concrete mixer, with 3 specimens in each group and a total of 36 groups, of which 18 groups were used for the cube compressive strength test and the other 18 groups for the tensile strength test. $100 \mathrm{~mm} \times 100 \mathrm{~mm} \times 400 \mathrm{~mm}$ nonstandard prism specimens, 3 in each group, a total of 18 groups, used for the flexural strength test. In accordance with the requirements of GB/T 50081-2002 Standard for Testing Methods on Mechanical Properties of Ordinary Concrete and CECS 13:2009 Standard for Testing Methods of Fiber Reinforced Concrete, tests on cube compressive strength, splitting tensile strength and bending strength of rubber concrete and laminated steel fiber rubber concrete were carried out.

\section{Analysis of test results}

\subsection{Test results}

The values of the cube's compressive strength, splitting tensile strength and bending strength obtained in this test are shown in Table 2.

Table2. Strength test values

\begin{tabular}{|c|c|c|c|c|c|c|c|}
\hline Rubber type & $\begin{array}{c}\text { Specimen } \\
\text { type }\end{array}$ & $\begin{array}{c}\text { The } \\
\text { compressive } \\
\text { strength of the } \\
\text { cube } \\
/ \mathrm{MPa}\end{array}$ & $\begin{array}{l}\text { Splitting } \\
\text { tensile } \\
\text { strength } \\
\quad / \mathrm{MPa}\end{array}$ & $\begin{array}{l}\text { Flexural } \\
\text { strength }\end{array}$ & $\begin{array}{c}\text { Compressive } \\
\text { strength } \\
\text { increase rate } \\
1 \%\end{array}$ & $\begin{array}{c}\text { Rate of } \\
\text { increase in } \\
\text { tensile } \\
\text { strength } \\
/ \%\end{array}$ & $\begin{array}{c}\text { Increase rate } \\
\text { of flexural } \\
\text { strength } \\
1 \%\end{array}$ \\
\hline \multirow{6}{*}{20 mesh } & RC20 & 49.13 & 3.35 & 5.57 & 0 & 0 & 0 \\
\hline & LS20-0.5 & 53.91 & 3.93 & 5.68 & 9.73 & 17.31 & 1.97 \\
\hline & LS20-1.0 & 55.28 & 4 & 5.82 & 12.52 & 18.81 & 4.49 \\
\hline & LS20-1.5 & 55.82 & 4.31 & 5.87 & 13.62 & 28.66 & 5.39 \\
\hline & LS20-2.0 & 58.68 & 4.29 & 6.3 & 19.44 & 28.06 & 13.11 \\
\hline & LS20-2.5 & 53.32 & 3.72 & 5.71 & 8.53 & 11.04 & 2.25 \\
\hline \multirow{6}{*}{40 mesh } & $\mathrm{RC} 40$ & 48.05 & 2.86 & 5.39 & 0 & 0 & 0 \\
\hline & LS40-0.5 & 53.32 & 4.1 & 6.16 & 10.97 & 43.36 & 14.29 \\
\hline & LS40-1.0 & 59.29 & 4.7 & 6.68 & 23.39 & 64.34 & 23.93 \\
\hline & LS40-1.5 & 61.96 & 4.81 & 6.43 & 28.95 & 68.18 & 19.29 \\
\hline & LS40-2.0 & 57.46 & 5.13 & 5.93 & 19.58 & 79.37 & 10.02 \\
\hline & LS40-2.5 & 58.26 & 4.86 & 5.86 & 21.25 & 69.93 & 8.72 \\
\hline \multirow{6}{*}{60 mesh } & RC60 & 46.22 & 2.69 & 4.89 & 0 & 0 & 0 \\
\hline & LS60-0.5 & 48.56 & 3.56 & 5.97 & 5.06 & 32.34 & 22.09 \\
\hline & LS60-1.0 & 54.28 & 3.86 & 6.2 & 17.44 & 43.49 & 26.79 \\
\hline & LS60-1.5 & 51.62 & 4.06 & 6.2 & 11.69 & 50.93 & 26.79 \\
\hline & LS60-2.0 & 44.28 & 4.18 & 5.97 & -4.2 & 55.39 & 22.09 \\
\hline & LS60-2.5 & 42.96 & 3.46 & 5.93 & -7.05 & 28.62 & 21.27 \\
\hline
\end{tabular}

Fig. 2, Fig. 3 and Fig. 4 respectively show the test results of the compressive strength, splitting tensile 
strength and bending strength of the laminated SFRC with different steel fiber content and different particle size of

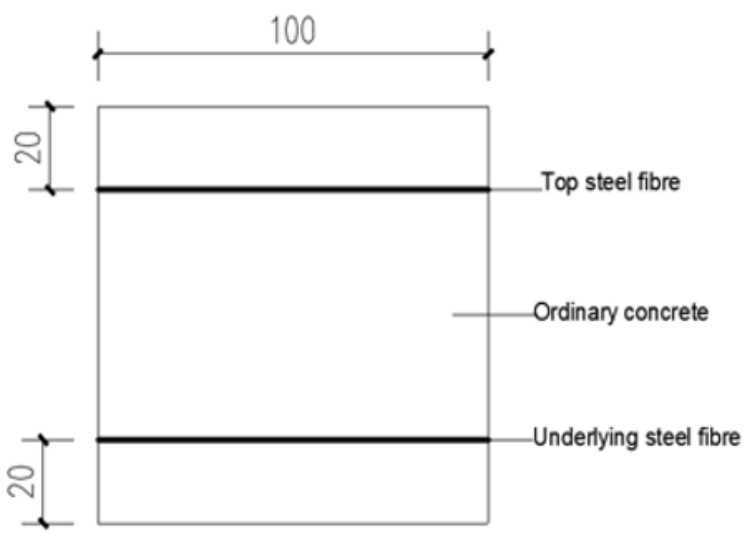

Figure 1. Schematic Diagram of Layered Concrete Specimen (Unit: $\mathrm{mm})$

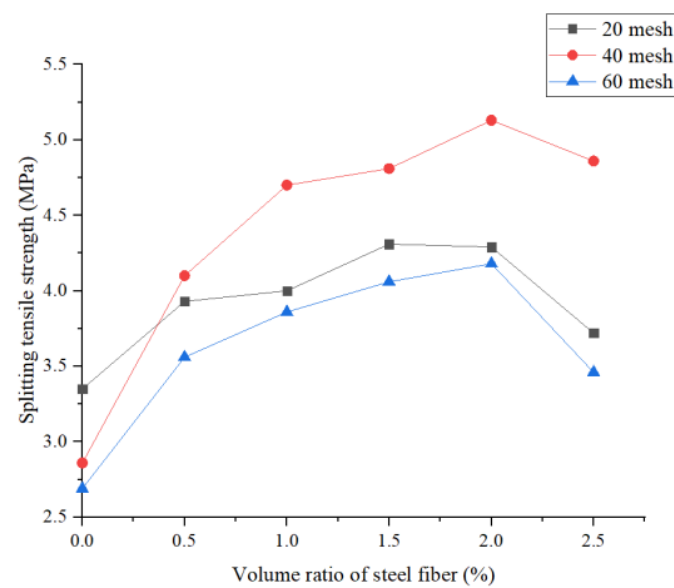

Figure 3. Splitting tensile strength of layered steel fiber rubber concrete rubber powder.

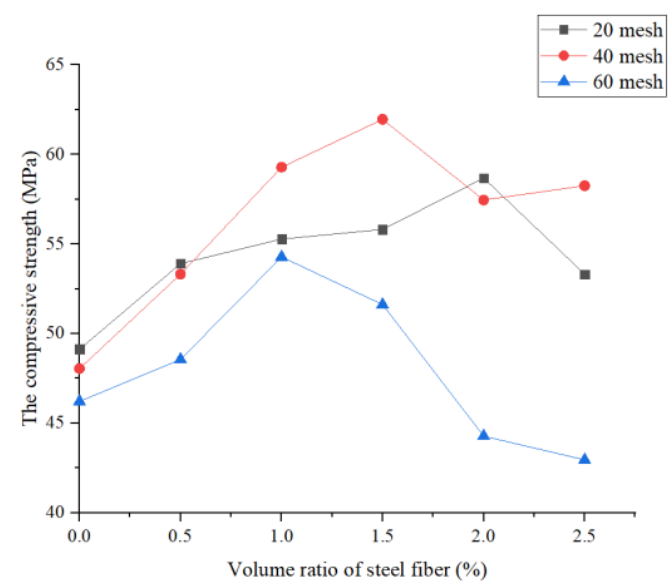

Figure 2. Compressive strength of layered steel fiber rubber concrete

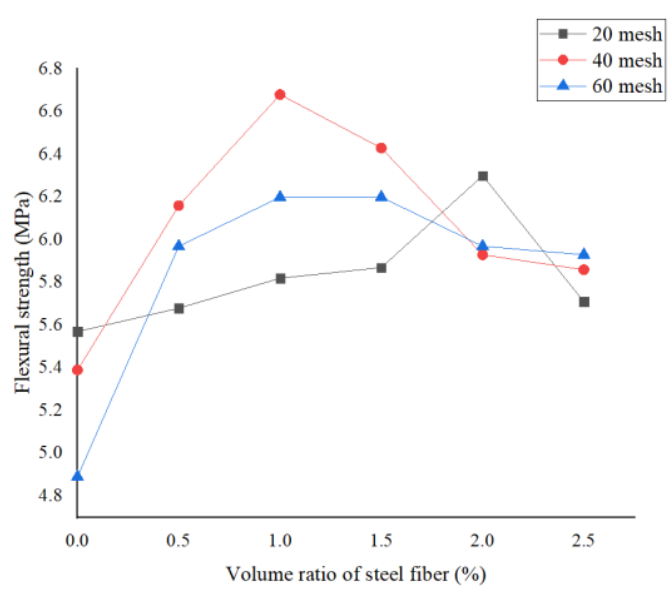

Figure 4. flexural strength of LSFRRC concrete

\subsection{Analysis of test results}

3.2.1 Cube compression test. According to the experimental results in Table 1 and Figure 2, when the rubber powder particle size is the same, the compressive strength of laminated steel fiber rubber concrete (LSFRRC) increases first and then decreases with the increase of the steel fiber content.However, the steel fiber volume fraction of LSFRRC is different when the rubber powder with different particle size is added.The compressive strength of LSFRRC-20 reached a peak value of $58.68 \mathrm{MPa}$ when $2.0 \%$ steel fiber was added to the upper layer, which was $19.44 \%$ higher than that of RC20. When $1.5 \%$ steel fiber is added to the upper layer, the compressive strength of LSFRRC-40 reaches a peak value of $61.96 \mathrm{MPa}$, which is $28.95 \%$ higher than that of $\mathrm{RC} 40$. When $1.0 \%$ steel fiber is added to the upper layer, the compressive strength of LSFRRC-60 reaches the peak value of $54.28 \mathrm{MPa}$, which is $17.44 \%$ higher than that of RC60.
The addition of rubber powder will reduce the mechanical properties of concrete to a certain extent, while the addition of steel fiber into ordinary concrete will not only improve the mechanical properties of concrete to a certain extent, but also make up for the weakness of the strength decline caused by rubber powder.As can be seen from Figure 3, when LSFRRC-60 reached the peak, the compressive strength began to decline rapidly. When the volume fraction of steel fiber on the top was $1.0 \%$, the compressive strength began to be lower than that of the benchmark concrete RC60. When the volume fraction was $2.5 \%$, the strength of RC60 decreased by $7.05 \%$ compared with that of RC60.The reason for this phenomenon is that with the increase of rubber powder particle size, the strengthening effect of steel fiber is not enough to offset the influence of 60 -mesh rubber powder on the too low strength.

3.2.2 Splitting tensile test. According to the experimental data in Table 1 and Figure 3, the splitting tensile strength of $\mathrm{RC}$, as the benchmark concrete, increases rapidly after the addition of steel fiber layer.In 
addition, the overall trend of LSFRRC splitting tensile strength is increased first and then decreased, and the splitting tensile strength is at the best state when the volume content of upper steel fiber is $1.5 \% \sim$ $2 \%$.Compared with the benchmark concrete RC20, RC40 and RC60, the maximum splitting tensile strength of layered steel fiber rubber concrete LS20, LS40 and LS60 is $28.66 \%, 79.37 \%$ and $55.39 \%$, respectively.

A drop in splitting tensile strength increase after first test phenomenon because of the elastic rubber effectively relieve internal stress concentration phenomenon of the concrete matrix, and the effective connection steel fiber cement substrate, with steel fiber content increase, between steel fiber to form the good fiber network, which formed steel fiber tensile enhancement effect is greater than the weak surface effect,Therefore, when the content of rubber is certain, the tensile effect of steel fiber is strong, and the strength of LSFRRC increases with the increase of the content of steel fiber.However, when the volume content of steel fiber reaches $1.5 \%-2 \%$, the steel fiber tends to be saturated in concrete, the weak bond between rubber particles and concrete matrix gradually appears, and the splitting tensile strength of LSFRRC begins to decline.

3.2.3 Flexural resistance test. Fig. 4 shows the test results of the flexural strength of laminated steel fiber rubber concrete with different steel fiber content and different rubber particle size.Fig. 4 shows that the bending strength of LSFRRC increases first and then decreases with the increase of the volume fraction of steel fiber.The bending strength of LSFRRC-20 reached the peak when the steel fiber with volume fraction of $2.0 \%$ was added to the upper layer, which increased by $13.11 \%$ compared with RC20.When $1.0 \%$ steel fiber is added to the upper layer, the bending strength of LSFRRC-40 reaches the peak, which is $23.93 \%$ higher than that of RC 40 . When $1.5 \%$ steel fiber is added to the upper layer, the peak flexural strength of LSFRRC-60 reaches 6.2MPa, which is $26.79 \%$ higher than that of RC60.Under the joint action of rubber powder and steel fiber, LS40-1.0 with steel fiber content of $1.0 \%$ has the best flexural strength and the best strengthening effect.

For this test, when the steel fiber content is relatively small, the distribution of steel fiber in concrete is relatively scattered and random, which is conducive to the formation of good bonding force between matrix concrete and steel fiber interface. With the increasing volume ratio of steel fiber, steel fiber becomes denser and even gradually stacking, which weakens the bonding force between steel fiber and concrete interface. When the content of steel fiber is too large to exceed a limit value, sufficient bonding between steel fiber and concrete cannot be formed, thus forming a weak surface inside concrete, in addition, with the increasing content of steel fiber in the upper layer, the scattered steel fiber accelerates the destruction of the compression zone.This is because the addition of steel fiber will decrease the flexural strength of the specimen.

\section{Conclusion}

With the increase of the content of upper steel fiber, the strength of LSFRRC normal mechanical properties showed a trend of increasing first and then decreasing, but the addition of rubber powder with different particle sizes would make the nodes of LSFRRC reach the peak strength different.The results show that :(1) The bonding property of 40 mesh rubber powder and steel fiber with $1.5 \%$ content is the best, which can improve the compressive strength of LSFRRC by synergistic effect.(2) When rubber powder and steel fiber are mixed at the same time, 40 mesh rubber powder and $2.0 \%$ steel fiber interact with each other, the splitting tensile strength of concrete can be enhanced best.(3) When rubber powder and steel fiber are mixed at the same time, 40 mesh rubber powder and 2.0\% steel fiber interact with each other, the splitting tensile strength of concrete is the best.

\section{References:}

1. Zhang Xianggang, Kuang Xiaomei, Niu Haicheng et al.Progress in Properties of Waste Rubber Modified Recycled Concrete [J]. Bulletin of Silicate,2017,36(12):4050-4059. (in Chinese)

2. Bie Sihan, Zhang Long, Wang Ligang, et al.Experimental Study on Mechanical Properties of Fiber-rubber Concrete [J]. Concrete and Cement Products,2015,(9):90-95.

3. Zhu Jiang, Li Xudong, Zhang Dongsheng.Research on Properties of Steel Fiber Modified Rubber Concrete with Different Distribution [J]. Concrete, 2013,(3):69-72.

4. Abdelaziz Meddah, Miloud Beddar,Abderrahim Bali. Use of shredded rubber tire aggregates for roller compacted concrete pavement[J]. Clean, 2014 regulation: 187-192.

5. Zhou Dong, Zheng Changlin, Zhu Zhengqi, et al.Experimental Study on Compressive Strength of Rubber Concrete [J]. Low Temperature Building Technology,2015 (11):10-11.

6. Yang Biao, Liu Yan.Research on Mechanical Properties of Rubber Particle Cement Matrix Composites [J]. Journal of Highway and Transportation Technology,2015(8):37-40.

7. Fan Xiaochun, Yuan Haiqing, $\mathrm{Lu}$ Zhean.Experimental study on mechanical properties of laminated steel fiber rubber concrete [J]. Journal of Wuhan University of Technology,2008(7):46-48. 